COMENTARIO DE JURISPRUDENCIA

\title{
La suficiencia de indicios en materia de tutela laboral. Comentario de jurisprudencia a la sentencia de unificación de jurisprudencia rol 12.362-2015, del 13 de junio de 2016 (acogido)
}

\author{
The sufficiency of evidence proof on the labor guardianship procedure. \\ Commentary on the judgment of unification of jurisprudence, \\ role 12.362-2015, june 13, 2016 (admitted)
}

Sebastián Pizarro Contreras

Abogado, Chile

\begin{abstract}
RESUMEN El presente comentario de jurisprudencia tiene por objeto exponer el criterio jurisprudencial de la Excma. Corte Suprema respecto de cuáles serían los efectos que en el juicio genera que el denunciante no incorpore, en su denuncia, todos los antecedentes en los que la fundamenta. En este contexto, se realiza una exposición de los diversos fundamentos expuestos por la Corte, efectuando un análisis crítico de los mismos, desde la interpretación gramatical, la oficialidad en tanto principio fundante del procedimiento, la Teoría del Acto Procesal, y las garantías a una Debido y Justo Procedimiento.
\end{abstract}

PALABRAS CLAVE Proporcionalidad, prueba de indicios, suficiencia de la demanda.

ABSTRACT The purpose of this commentary on jurisprudence is to set out the jurisprudential criterion of the Supreme Court regarding what would be the effects that in the trial generates that the complainant does not incorporate, in his complaint, all the legal precedents on which it is based. In this context, an exposition of the various grounds presented by the Court is made, making a critical analysis of them, from the grammatical interpretation, the officiality as the founding principle of the procedure, the Theory of the Procedural Act, and the guarantees to a Due and Just Procedure.

KEYWORDS Proportionality, evidence proof, demand sufficiency. 


\section{Contexto, partes y derrotero}

\section{Antecedentes del caso}

Ante el Juzgado de Letras del Trabajo de Chaitén (RIT T-1-2013), interpone denuncia de Tutela por Vulneración de Derechos Fundamentales el docente Sergio Lamas Alarcón, expresando que habrían sido afectados con ocasión del despido los derechos amparados en los artículos 19 números 1, 2 y 4 de la Constitución Política de la República. Señala una serie de indicios, destacándose el haber sido sumariado por hechos ocurridos tras solo tres días de haber iniciado su prestación de servicios en la Escuela Casa de Pesca, haber sido suspendido de sus funciones durante 11 meses, ser sobreseído de las acusaciones que le fuesen formuladas, y finalmente haberse puesto término a la relación laboral de una forma que él considera indebida.

La demandada, I. Municipalidad de Chaitén, opone excepciones perentorias y contesta demanda. En lo que resulta pertinente y relevante, una de las excepciones perentorias opuestas guarda relación con lo dispuesto en los artículos 490 inciso $1^{\circ} \mathrm{y}$ 493 del Código del Trabajo. La lectura que la parte expresa al respecto, es que como la actora no acompañó antecedentes a su denuncia de conformidad al artículo 490 del Código, no es posible afirmar la existencia de indicios suficientes acerca de que se ha producido la vulneración. A mayor abundamiento, señala que de los meros dichos del actor no pueden surgir efectos procesales definitivos a favor suyo o en contra de la demandada. Culmina expresando que, para el evento que la denuncia continúe tramitándose no obstante obviarse el acompañarse los antecedentes aludidos en el artículo 493 del Código del Trabajo, se estaría vulnerando el principio al debido proceso, abriendo la ventana a la arbitrariedad judicial.

La sentencia del tribunal chaitenino, a propósito de la excepción relatada, resuelve en su considerando décimo:

[Q]ue, respecto a esta excepción, y escuchadas las partes y sus alegaciones correspondientes y a través de la sola lectura de la demanda, en esta se ha redactado en forma clara y precisa los hechos en que fundamenta la vulneración señalada. Por otra parte, la historia de la Ley, en relación a lo indicado en el artículo 490 del cuerpo legal ya citado, se redactó para los fines de evitar justamente demandas temerarias y/o abusos de accionar por cualquier vulneración. Es más, los antecedentes del mismo se obtienen en forma fidedigna justamente en la audiencia de Juicio, mediante los testimonios y el relato de cómo ocurrieron los hechos, por ello se debe aplicar la proporcionalidad del núcleo esencial en que se ampara esta acción de tutela. Por todo ello, esta excepción será rechazada.

El tribunal, ya a propósito de las elucubraciones que culminan resolviendo la existencia de derechos fundamentales conculcados, expresa en el considerando décimo quinto: 
[Q]ue, el demandado, a quien correspondía el peso de la prueba, no acreditó haber tomado ninguna medida eficaz para que el demandante ejerciera efectivamente su labor de docente en la Escuela de Chumeldén, lo que resulta evidente del testimonio entregado por la Jefa del Dem doña Margarita Zamora, y del propio Alcalde, este último en contradicciones con lo manifestado por la Sra. Zamora y además manifestando que NO SABIA en qué momento el fiscal suspendió al Sr. Lamas; que no sabía lo que había dictaminado la Contraloría; que él tomó la decisión de sumariar nuevamente al Sr. Lamas días después de haber conversado con él al parecer en Junio; lo que se contrapone evidentemente con los documentos exhibidos, en especial de su decisión de sumariar al demandante que lo hizo con fecha 30 de Mayo de 2013, conforme además con la prueba documental signada con el $\mathrm{N}^{\circ}{ }_{12}$. Todo lo antes indicado, se determinó en los hechos a probar que el Tribunal fijó.

La vencida I. Municipalidad de Chaitén opone recurso de nulidad en contra de la mentada sentencia basado en el artículo 477 del Código del Trabajo, teniendo por base en lo relevante una infracción de ley, cual sería la del artículo 490 inciso $1^{\circ}$ del mismo Código, reiterando esencialmente los mismos argumentos que sustentaron la excepción opuesta al contestar la denuncia.

La I. Corte de Apelaciones de Puerto Montt, en causa Rol Ref.Lab. N. ${ }^{\circ}$ 75-2014, resuelve anular la sentencia de primera instancia, indicando lo que se reproduce:

Se reproducen los considerandos sexto y séptimo de la sentencia de nulidad. Y, se tiene, además, presente. Que, se ha anulado la sentencia de primera instancia que resolvió sobre la tutela. Que, la demanda de tutela no cumplió con los requisitos del art. 490, inciso primero del Código del Trabajo, en cuanto a acompañar los antecedentes fundantes de la vulneración denunciada. Y. vistos, lo dispuesto, además, en los artículos 477 y siguientes del Código del Trabajo, se declara: Que, se rechaza, con costas, la demanda de tutela de derechos fundamentales interpuesta por Sergio Lamas Alarcón en contra de la Municipalidad de Chaitén.

Finalmente, la ahora vencida actora dedujo recurso de Unificación de Jurisprudencia en contra de la sentencia de la I. Corte de Apelaciones de Puerto Montt.

\section{La cuestión planteada ante la Corte Suprema y su resolución.}

El objeto del fallo de unificación en el presente caso, no es sino esclarecer conforme lo establece la Excma. Corte Suprema, «cuáles son los efectos que en el juicio genera que el denunciante no incorpore, en la primera presentación que formula al tribunal, todos los antecedentes en los que la asienta».

La Corte Suprema sobre la base del Recurso de Unificación deducido, en específico de la sentencia impugnada y de la de contraste, identifica la existencia de dos interpretaciones opuestas sobre la materia en comento, a saber: 
a) Si el denunciante no acompaña los antecedentes en que fundamenta la denuncia de vulneración de Derechos Fundamentales, necesariamente aquella deberá ser declarada inadmisible. Ello, pues «solo una bien asentada puede explicar si la vulneración existió o no, por lo que no se puede pretender formular una mencionando únicamente los presuntos antecedentes, esperando que la contraparte los aporte».

b) Los requisitos del artículo 490 del Código del Trabajo deben entenderse ligados con la facilidad probatoria del 493 del mismo. De ahí que, basada en el principio de la tutela efectiva de los derechos de los trabajadores, esta interpretación señala que «si el denunciante no acompaña en dicho libelo los antecedentes o si el juez estima que no son suficientes para generar la sospecha razonable de que se verificó una infracción a los derechos fundamentales, la consecuencia inevitable es que no se producirá el efecto que genera la última disposición citada, por ende, recaerá en el denunciante la obligación de demostrar y acreditar en la audiencia de juicio la efectividad de los actos denunciados».

El máximo Tribunal termina resolviendo la disyuntiva presentada en el considerando séptimo de la siguiente forma:

Los artículos 490 y 493 del Código del Trabajo no deben interpretarse de manera aislada, pues sus normas se complementan, ya que el primero impone una exigencia lógica toda vez que el segundo consagra una suerte de reducción probatoria con la finalidad de dar tutela efectiva a los derechos fundamentales de los trabajadores, que cobra relevancia al momento en que se dicta sentencia, oportunidad en la que se debe determinar quién debe soportar el costo por no haberse probado plenamente un determinado hecho, existiendo indicios de su ocurrencia. En ese contexto, si la denuncia cumple los requisitos que señala la primera norma y son suficientes para generar en el juez la sospecha razonable que se infringieron derechos fundamentales del denunciante, se aliviana o facilita la carga probatoria que le asiste, correspondiéndole al denunciado explicar los fundamentos de las medidas adoptadas y su proporcionalidad, en caso contrario, debe asumir el peso de la prueba en su integridad; sin que pueda inferirse que para admitir a tramitación la denuncia es menester que se acompañe la prueba material de la cual surgen los antecedentes que se indican en el libelo respectivo.

El presente comentario de jurisprudencia tiene por objeto analizar los fundamentos que tuvo la E. Corte Suprema para terminar decantándose por una posición, trayendo a colación material dogmático y positivo de forma crítica vis a vis su decisión. 


\section{Comentario de jurisprudencia}

La noción de «antecedente» del artículo 490 inciso segundo del Código del Trabajo

Básica en el hilado argumental del supremo tribunal, es la comprensión que se realiza del concepto de «antecedente», en el marco del artículo 490 inciso segundo del Código del Trabajo. En base a la misma es que luego se efectúan consideraciones relativas a apercibimientos y admisibilidad de la denuncia.

En el considerando cuarto de la sentencia, la Corte establece lo siguiente:

Que, en consecuencia, atendido el tenor literal de la disposición en análisis, si el sentenciador de base advierte que la denuncia no contempla una precisa y detallada exposición de los hechos que configurarían la vulneración de derechos fundamentales, corresponde que ordene que se dé cumplimiento a lo que dispone el inciso segundo del artículo 49o, fijando el plazo fatal de cinco días. Asimismo, como una acepción de la palabra «antecedente», según el Diccionario de la Lengua Española, es «acción, dicho o circunstancia anterior que sirve para juzgar hechos posteriores", por lo tanto, la expresión «antecedentes» es sinónimo de referencias, datos y condiciones, y no del documento material que los contiene, esto es, del medio probatorio propiamente tal, se debe inferir que la frase que la Ley 20.260 introdujo al inciso en comento solo tuvo por finalidad reforzar la idea que contiene su apartado $1 .^{\circ}$, en el sentido que la denuncia debe bastarse a sí misma y ser clara y precisa.

En todo caso, como dicha norma no señala un apercibimiento, tampoco una sanción en el caso que el denunciante incumpla el mandato judicial, no corresponde que la denuncia sea declarada inadmisible o se la desestime desde ya, menos que se la rechace una vez tramitado el juicio íntegramente. Para ello, habría sido necesario que el legislador lo hubiera señalado expresamente, v.gr., como lo hizo tratándose del artículo 54-1 de la Ley 19.968, en la medida que señala que si en el control de admisibilidad se advierte que la demanda no cumple los requisitos formales que establece el artículo 57, el tribunal debe ordenar que se subsanen sus defectos en el plazo que fije, bajo sanción de tenerla por no presentada.

Vamos por parte. Lo primero es evaluar si acaso la forma en la que la Corte Suprema despeja la significancia de la palabra «antecedente» en la norma señalada es correcta o no. El resultado, se anuncia desde ya, no es feliz, pudiendo arribar a dicha conclusión en virtud del siguiente análisis.

\section{No es posible obviar el contexto normativo y la operatividad de la palabra}

Derechamente, no es lo mismo emplear el Diccionario de la Real Academia Española de la Lengua (en adelante, DRAE) para establecer el recto sentido y alcance de una 
palabra en particular, que para ir delineando en el contexto de una institución jurídica (a saber, la tutela de Derechos Fundamentales) su relevancia y alcance operativo. No desentenderse de esta dinámica, implicar aceptar la posibilidad que, por ejemplo, en el contexto de los modos de adquirir en el Código Civil podamos eventualmente entender a la tradición como la "transmisión de noticias, composiciones literarias, doctrinas, ritos, costumbres, etcétera, hecha de generación en generación», por el sólo hecho que así la define en alguna acepción el DRAE. Ininteligible.

El Código Civil ilumina mediante su normativa sobre interpretación, el cómo comprender en el escenario del procedimiento de tutela de Derechos Fundamentales el concepto de «antecedentes». Con precisión, dos son los artículos útiles, a saber, 20 y 22 inciso $1^{\circ}$ de dicho código.

De este dúo, en primer lugar, es posible establecer que cardinal es dentro de la comprensión jurídica de un concepto, es que el legislador lo haya definido expresamente para ciertas materias, dado que en dicho ámbito se les dará su sentido legal. Para el caso contrario, se les entenderá según su sentido natural y obvio (Claro Solar, 1992: 122-123). ${ }^{1}$ Ducci señala a propósito de este elemento de interpretación gramatical, que «durante mucho tiempo nuestros tribunales estimaron que este sentido natural debía encontrarse en el Diccionario de la Real Academia Española; hoy día, y considerando los cambios que experimenta el lenguaje, se ha reaccionado frente a este criterio y se ha considerado que el sentido natural de una palabra o frase es el que se le atribuye en el medio que la emplea» (Ducci, 2005: 91). En términos resumidos, se interpretan según su sentido natural y obvio todas aquellas palabras que, sin entenderse como técnicas, el legislador tampoco las ha definido.

En segundo lugar, el artículo 22 inciso primero del Código Civil establece el elemento interpretativo lógico en razón del cual el intérprete debe buscar «la concordancia entre las distintas partes de la ley, y esta concordancia debe ser consecuente, es decir, armónica». Andreucci advierte la escasa cantidad de sentencias emanadas

1. «Es pues, al tenor literal lo primero a que debe atenderse y para fijarlo el Código ha cuidado de dar algunas otras reglas. Las palabras de que el legislador se sirve pueden tener dos significaciones: el sentido vulgar y el sentido técnico. Según el artículo 20, "las palabras de la ley se entenderán en su sentido natural y obvio, según el uso general de las mismas palabras", es decir, el uso de la gente educada. El diccionario de la lengua publicado por la Real Academia Española, goza a este respecto de gran autoridad. "Pero cuando el legislador, agrega el artículo 20, las haya definido expresamente para ciertas materias se les dará en estas su significado legal". Por la inversa, según el artículo 21, "las palabras técnicas de toda ciencias o arte se tomarán en el sentido que les den los que profesan la misma ciencia o arte; a menos que aparezca claramente que se han tomado en sentido diverso". Es de suponer que el legislador conozca bastante el idioma en que legisla y sea suficientemente instruido en la ciencia o arte para dar a las palabras de la lengua y a las palabras especiales de la ciencia o arte a que se refiere, el significado que le es propio; en el caso contrario, es necesario que ello aparezca de manifiesto y con toda claridad» (Claro Solar, 1992: 122-123). 
de la Corte Suprema empleando este elemento, empero, señala dos elementos que caracterizan su ratio en general:

Que no exista contradicción entre las distintas partes de la ley; y que el resultado de la aplicación de la norma sea acorde con la finalidad que persiguió el legislador al dictar la ley que se interpreta, lo cual es correcto. Un comentario en otra línea es destacar que jamás sostiene la Corte Suprema que este elemento se aplica directamente para determinar el sentido de la ley; siempre sostiene que es sucedáneo del tenor literal, al igual que los otros elementos de interpretación, en circunstancias que en toda interpretación siempre debe existir conclusiones lógicas (Andreucci, 2008: 29).

En conclusión, en relación a la interpretación que deberá dársele al significado de un concepto deberá considerarse el uso natural y obvio que se le atribuye en el medio que se le emplea, y que como fruto de aquel, la hermenéutica resultante en razón de la aplicación del principio de lógica, sea armónica con el contexto en la que éste se sitúa.

Finalmente, menester resulta útil en esta trama, tener presente cuatro normas del Código del Trabajo, artículos 446, 490, 492 y 493. De su comprensión compleja, es posible concluir que la noción de «antecedentes» malamente podría llegar a ser entendida como sinónimo de referencias, datos y condiciones al modo del DRAE seguido por la sentencia en comento, y con ello, asimilable a la noción de hechos y su exposición, conforme hila la Corte su argumento.

A partir de las mismas, un análisis exegético y coherente relativo al empleo de la voz «antecedente(s)», debiera, además de tener presente las fragilidades lógicoconceptuales de la Corte en su interpretación, obedecer a lo siguiente:

1. El legislador particulariza los requisitos de existencia de la denuncia de vulneración de Derechos Fundamentales, en relación a los de una demanda, aludiendo a estos últimos en el artículo 490. El uso de la voz «además», es fiel reflejo de ello.

2. En efecto, dentro de los requisitos del artículo 446 , se incluye en su $\mathrm{N}^{\circ} 4$, «La exposición clara y circunstanciada de los hechos y consideraciones de derecho en que se fundamenta»; mientras que el 490 indica que «La denuncia deberá contener, además de los requisitos generales que establece el artículo 446, la enunciación clara y precisa de los hechos constitutivos de la vulneración alegada acompañándose todos los antecedentes en los que se fundamente.

3. Se puede concluir que los hechos que configurarían la eventual vulneración de derechos fundamentales, son una especificación de los requisitos generales de los libelos laborales contenidos en el artículo 446 del Código.

4. Renglón seguido, y siguiendo con el artículo 490 del Código, se señala que la denuncia de vulneración, «además» de los hechos en que se funda aquella, deberá acompañar todos los antecedentes en que se funda.

5. De seguir una línea interpretativa como la de la Corte Suprema, que hace sinónimos «hechos» $\mathrm{y}$ «antecedentes» fundantes, se produciría una contradicción nor- 
mativa, en razón de la cual, además de la «enunciación clara y precisa de los hechos constitutivos de la vulneración», deberá acompañarse a tal denuncia, redundantemente, «una precisa y detallada exposición de los hechos que configurarían la vulneración de derechos fundamentales», estableciéndose que para el evento que aquella no los contenga el juez deberá conceder un plazo fatal de cinco días para su incorporación. ¿Será este un problema de técnica legislativa?

6. La respuesta a la anterior pregunta es negativa, como ya es posible anticipar, pues el problema es, en estricto rigor, uno netamente interpretativo cuyos corolarios desencadenan en lo absurdo, rompiéndose los elementos lógico y gramatical. Y claramente, como se tendrá oportunidad de revisar más adelante, tampoco es un problema de tutela judicial efectiva de los Derechos. Al alero de lo resuelto por la Corte, bastaría con describir con precisión circunstancias contundentes, conexas, coherentes y precisas - «antecedentes» $y$ «hechos configurantes de la eventual vulneración», al mismo tiempo-, para que la denuncia sea plenamente admisible al haberse acompañado aquellos. No sin olvidar, por cierto, que además al haberse acompañado antecedentes, resultarán indicios, siendo en consecuencia resorte de la denunciada explicar los fundamentos de las medidas adoptadas y su proporcionalidad, de conformidad al artículo 493 del Código del Trabajo. Es decir, no aportando nada diverso a un buen relato, que únicamente en razón de su estructura y coherencia podría gozar de credibilidad, el sistema laboral culmina amparando denuncias aventuradas o temerarias, en las que expresamente el Código a fin de evitarlas agrega a los hechos el que se acompañen antecedentes que sustenten el correlato fáctico.

7. En la misma línea del punto anterior, de seguir una línea argumentativa como la de la Excma. Corte Suprema, se abre la peligrosa posibilidad, de conformidad con el artículo 492 del Código del Trabajo, que surgiendo de la mera exposición detallada y precisa de los hechos («antecedentes») lesiones de especial gravedad o cuando la vulneración pueda causar daños irreversibles, el juez de oficio o petición de parte dispondrá en su primera resolución la suspensión de los efectos del acto, bajo apercibimiento de multa de cincuenta a cien UTM. Además, ello podrá hacerlo en cualquier tiempo desde que cuente con dichos antecedentes; precisión que refuerza el que no es dable tener por sinónimos «antecedentes» $\mathrm{y}$ «hechos» en este entramado.

En efecto, la peligrosidad reseñada adquiere ribetes fundamentales ligables a las garantías del debido proceso de proseguir en la línea unificada por el máximo Tribunal, al contrariar con ella principios tales como el de contradicción y el derecho a ser oído. Se argüirá en contrario, que esto es reflejo de las potestades cautelares del juez en razón de lo inspirado por el artículo 429 del Código del Trabajo, empero, tanto la posibilidad de suspender de los efectos del acto como los apercibimientos aplicables para el evento que el juez estime la denunciada no ha dado cumplimiento ello, dan cuenta de la existencia de una tutela anticipatoria. Anota Palavecino al respecto, que «la "suspensión de los efectos del acto impugnado" prevista en el artículo 492 del 
Código del Trabajo es la anticipación del "cese inmediato" del comportamiento antijurídico que deberá ordenar el juez en la sentencia definitiva conforme el artículo 495 número 2 del mismo cuerpo legal, operando el mismo apercibimiento de multa en ambos casos. La cognición sumaria de verosimilitud la hará el juez a partir "de los antecedentes acompañados al proceso". [...] Resulta altamente cuestionable desde el punto de vista de la garantía del debido proceso que la parte que no ha sido previamente oída, deba soportar de inmediato y sin posibilidad de impugnación, el perjuicio sobre su interés que le provoca la resolución del tribunal» (Palavecino, 2014: 42). Es decir, mediando un mero relato asimilable sin coherencia alguna a antecedentes, sin audiencia, sin posibilidad de recurrir ${ }^{2}$, y con el riesgo latente que apercibimientos no menores se repitan al menos hasta la realización de la audiencia preparatoria, el denunciado se sujeta a las reglas de un proceso que, de debido, tiene bien poco en definitiva.

De esta forma, la Corte Suprema sin mediar autorización legislativa alguna, permea nociones ausentes en la comprensión de los Derechos Fundamentales y su núcleo, mediante la estructuración de una específica lingüística jurídica en la sentencia. En efecto, siguiendo a Glendon, mediante «la vía de la interpretación, las sentencias de los tribunales pueden proporcionar, y a menudo proporcionan, ideas que no figuran en el texto de nuestros documentos fundamentales» (Glendon, 1998: 93). Sentencias como la presente, resultantes de la decisión de un recurso de unificación resuelto por la Corte Suprema, cumplen un particular rol lingüístico configurador de sentido, permeando a los especialistas y legos, a la forma en que estos defienden los intereses de sus representados. Esta forma de configurar la construcción de la Tutela de los Derechos Fundamentales va obviando peligrosamente factores tales como la congruencia con el entramado constitucional y legal, o la lógica interna de los fallos, defendiendo sin más una particular interpretación. Lo que la Corte hace, en fin, mediante un ejercicio como el presente, es instalar un discurso político definido, colocándose como guardián de la posición jurídica de la tradicionalmente vista como la más débil de las partes de la relación de trabajo, aun cuando con ello se afecten otros derechos esenciales en juego, incluso contra legem como en el presente caso.

8. En consecuencia, es evidente que debe entenderse en un sentido no equivalente las voces «hecho» $\mathrm{y}$ «antecedente», sino que muy por el contrario, debe brindárseles un sentido de necesaria concatenación, lógico, y complementario dentro de la tutela efectiva de los derechos y en el contexto del Debido Proceso. Se reitera la idea, «antecedente» no puede representar un sinónimo de «hecho»: antecedente es el soporte material y probatorio en razón del cual sea posible sustentar y dotar de credibilidad a la batería fáctica que constituye la vulneración alegada. Solo en razón de ello podrá entenderse al menos dentro de un marco de razonabilidad y coherencia jurídica, que

2. Inciso segundo del artículo 492 del Código del Trabajo. 
la constitución de indicios suficientes, no el establecimiento de hechos indubitados por la sola circunstancia que el denunciante señale un relato sin sustento material, permita el nacimiento de la obligación para el denunciado de dar razón de las medidas implementadas y su proporcionalidad. Es así como podrá entenderse a la denuncia, parafraseando a la sentencia en comento, como una que se baste a sí misma, clara y precisa.

\section{Apercibimientos y admisibilidad. Un tema de teoría del acto jurídico procesal}

Expuesto lo anterior, se ha dejado ex profeso un punto pendiente para su revisión. Tal es relativo al del apercibimiento contenido en el inciso $2^{\circ}$ del artículo 490 del Código del Trabajo y su incidencia en la admisibilidad de la denuncia.

Desde la literalidad del artículo, es posible extraer que para el evento que la denuncia no contenga los antecedentes fundantes propios del inciso primero del artículo 490 , el juez concederá un plazo fatal de cinco días para que estos sean incorporados. La significancia que debe dársele en este escenario a la palabra «incorporación» reafirma la argumentación vertida en el punto anterior, en el sentido que las palabras deben gozar de una interpretación gramatical y lógica que les permita engarzarse bien en el contexto e institución en el que son empleadas. Dicho de otro modo, no es dable pensar en la «incorporación» en tanto forma mediante la cual se van rindiendo en la audiencia de juicio, las pruebas que fueron ofrecidas en la audiencia preparatoria, puesto que estamos en una etapa previa incluso a que el Tribunal establezca la admisibilidad de la denuncia laboral de tutela. Así, «incorporación» alude a la forma en que el legislador expresamente contempla el modo en la que los antecedentes fundantes de la denuncia ingresen al juicio (inciso $1^{\circ}$ del artículo 490), estableciendo un plazo fatal de cinco días para el caso que la denuncia no los contenga.

La operatividad del artículo pareciera ser clara, en particular desde su tenor literal. Empero, y en un claro torcimiento de la lógica y la extensión natural y obvia de la palabra en su contexto jurídico, la sentencia comentada indica a propósito del inciso segundo del artículo 490 del Código del Trabajo, lo siguiente:

En todo caso, como dicha norma no señala un apercibimiento, tampoco una sanción en el caso que el denunciante incumpla el mandato judicial, no corresponde que la denuncia sea declarada inadmisible o se la desestime desde ya, menos que se la rechace una vez tramitado el juicio íntegramente. Para ello, habría sido necesario que el legislador lo hubiera señalado expresamente, $v$. gr., como lo hizo tratándose del artículo 54-1 de la Ley 19.968, en la medida que señala que si en el control de admisibilidad se advierte que la demanda no cumple los requisitos formales que establece el artículo 57, el tribunal debe ordenar que se subsanen sus defectos en el plazo que fije, bajo sanción de tenerla por no presentada. 
En este punto, soy de la opinión que la Excma. Corte Suprema se aparta de la aplicación de instituciones jurídicas relativas a los actos jurídicos procesales.

El Tribunal expresa que el artículo 490 inciso segundo del Código del Trabajo no establece un apercibimiento y tampoco una sanción para el evento que la denuncia por vulneración de Derechos Fundamentales no acompañe todos los antecedentes en los que se funde. A fin de simplemente ilustrar a la Corte, vale la pena leer la terminología empleada más allá de la técnica legislativa. El inciso segundo habla de la concesión de un plazo fatal de 5 días para la incorporación de tales antecedentes. Plazo, nótese, fatal. ¿Qué entender por plazo fatal? No existiendo definición de ello en el Código del Trabajo, y sin necesidad de recurrir a la doctrina, el Código del Procedimiento Civil (C.P.C) ofrece una pauta que describe su racionalidad, prescrita en el inciso primero de su artículo 64.

Así, «plazo fatal» será aquel que, expirando por el simple transcurso del tiempo, extingue la posibilidad de ejercer o la oportunidad para ejecutar el acto que debió ejercitarse dentro de él. Deberá tenerse presente lo que en su parte final el inciso transcrito expresa en relación a las facultades del juez una vez vencido el plazo fatal: no siendo necesario certificación de dicho vencimiento fatal, "proveerá lo que convenga para la prosecución del juicio». Llevado esto al caso en comento, ¿deberá entenderse este mandato como un llamado para que el juez, no obstante el vencimiento de un plazo fatal de cinco días para acompañar antecedentes, igualmente continúe con la tramitación de un juicio de esta naturaleza?

Una primera pista para lograr una adecuada respuesta a tal pregunta, debiera partir por indicar que, ante la ausencia de definición en el contexto jurídico laboral de «plazo fatal» y no obstante la norma del artículo 64 inciso primero del Código de Procedimiento Civil se encuentra emplazada en dinámicas procesales propias de lo civil, el contenido del artículo 3 del mismo cuerpo legal -emplazado dentro de las «Disposiciones comunes a todo procedimiento», Libro I- hace devenir en plenamente aplicable el artículo 64 inciso primero de Código de Procedimiento Civil en sede laboral. Esto, con una sola salvedad de conformidad con el artículo 432 inciso primero del Código del Trabajo, para el evento que las normas de los Libros I y II del Código de Procedimiento Civil contradigan los principios del procedimiento laboral, disponiendo en tal caso el Tribunal la forma en que se practique la actuación. Al amparo de esto, el rol que juega el adjudicador en esta línea resulta ser elemental.

A continuación, y sin rodeos, la pregunta que se desgaja de la consideración anterior, es la siguiente: asumido que la oficialidad del artículo 429 del Código del Trabajo es un principio formativo del procedimiento laboral, que afecta y direcciona la actividad del juez, ¿tendrá alguna incidencia para la aplicabilidad del artículo 64 inciso primero del Código de Procedimiento Civil en sede laboral, lo dispuesto en el 429 del Código del Trabajo? De tal norma, es posible extraer que el juez está dotado de atribuciones que amparan tanto evitar que el proceso se paralice como se prolongue 
indebidamente, pudiendo incluso corregir vicios que observe (lo que da pie para entender que no se precisa para ello solicitud de parte) en la tramitación del juicio, lo que necesariamente apela al inicio del mismo. Lo cual aplicado al caso que motiva el presente comentario de jurisprudencia, lleva a hablar de la manera en la que puede tenerse por iniciado el procedimiento de Tutela Laboral.

Tener por iniciado tal procedimiento de manera válida, aun cuando parezca excesivamente básico traer aristas como esta, implica decir que en vistas a tal fin, el legitimado activo debe poner en marcha la actividad judicial mediando las formas que la legislación establece. Por ende, como en el escenario de análisis, si han sido «lesionados derechos fundamentales en el ámbito de las relaciones jurídicas cuyo conocimiento corresponde a la jurisdicción laboral» (artículo 486 inciso primero del Código del Trabajo), pero dicha afectación «se hubiere producido con ocasión del despido», tal legitimación activa «corresponderá exclusivamente al trabajador afectado» (artículo 489 inciso primero del Código del Trabajo). La forma prescrita por el legislador laboral para estos efectos es mediante la interposición de una denuncia, acto jurídico procesal que tal como la gran mayoría, es esencialmente solemne, precisándose del cumplimiento de particulares requisitos cuyo cumplimiento habilitan al juez determinar su admisibilidad y, en fin, que aquella sea tramitada.

Los requisitos de la denuncia, como en reiteradas ocasiones se ha expuesto en este comentario, se encuentran en el artículo 490 del Código del Trabajo: además de los requisitos del artículo 446 del mismo Código, ya citados, el legislador hace una precisión expresa en relación a la significancia de los «hechos», señalando que deberá contenerse en la denuncia, «la enunciación clara y precisa de los hechos constitutivos de la vulneración alegada acompañándose todos los antecedentes en los que se fundamente». Para el caso que estos antecedentes no se incorporen a la denuncia, la ley imperativamente comanda al juez a que otorgue un plazo fatal de cinco días para ello. Cumpliendo entonces, y sólo entonces la denuncia con los requisitos, o dándose cumplimiento por parte del legitimado activo en vistas a incorporar los antecedentes fundantes dentro de plazo, la denuncia deberá tenerse por admitida a tramitación de conformidad al procedimiento de aplicación general (artículo 491 del Código del Trabajo). ${ }^{3}$

3. A este entramado legal, menester resulta agregar algunas normas que alimentan la argumentación expuesta. La E. Corte Suprema, desde hace largo tiempo, ha expresado que de lo señalado en el artículo 64 del Código de Procedimiento Civil, se infiere que el uso de las expresiones «en» $\mathrm{o}$ «dentro de» ha de entenderse como caracterización de los plazos fatales. Así, al tenor de lo dispuesto en el artículo 12 del Código Civil, en relación con el artículo 5 del Código del Trabajo, es posible concluir que «el no ejercicio de un derecho que sólo puede hacerse valer legalmente dentro de un plazo fatal importa una verdadera renuncia tácita y la caducidad de este derecho». Así mismo, también ha señalado que «El precepto del artículo 49 del Código Civil establece la caducidad, o sea, la falta de validez de los actos que se ejecutan fuera del plazo que señala la ley». En Repertorio de Legislación y Jurisprudencia Chilenas, Código Civil 
¿Qué pasa entonces si la denuncia no cumple con los requisitos prescritos para admitirla a tramitación? Pues bien, es la propia ley la que abre la posibilidad ante una denuncia que imperfectamente no acompañe los antecedentes, pudiendo ser incorporados al proceso, por parte del trabajador denunciante, dentro del plazo fatal de cinco días. Por ende, si el propio legitimado activo es quién no cumple con el mandato legal dentro de dicho plazo, parafraseando al artículo 64 del Código de Procedimiento Civil, la posibilidad u oportunidad de ejercer únicamente el trabajador afectado su derecho se ha extinguido. En consecuencia, el Tribunal no podrá jamás sobre la base de la oficialidad del artículo 429 del Código del Trabajo corregir un vicio de esta naturaleza, so riesgo de asumirse ya sea como parte, o coadyuvante del legitimado activo, tal vez como escudero del litigante temerario y/o, por qué no, como un adjudicador derechamente prevaricador ${ }^{4}$.

Es más, es el propio principio de oficialidad el que impone al juez la obligación de tomar las medidas necesarias para que el proceso no se extienda de forma indebida. Entendido esto, huelga preguntarse empleando el mismo término legal, ¿es debido por parte de la judicatura laboral extender la duración de un juicio entendiendo como admitida una denuncia, cuando es el propio actor quién no ha cumplido con los requisitos que la ley impone para entenderla como formalmente admisible? Resulta claro que la respuesta es negativa, y que una positiva a esa interrogante sin dejo a dudas tomará como suyos los argumentos expuestos por la Corte. Con todo, y con lo expuesto, indudable es, que desde categorías procesales estrictas, se está en presencia de un acto jurídico procesal ineficaz, por carecer la denuncia de los requisitos que impone la ley para ser admitida a tramitación.

Así, con casi todas las premisas expuestas sobre la mesa dirigidas a derrotar la argumentación del fallo comentado, ex profeso se ha dejado para el final uno de las más curiosas tesis esgrimidas por la Excma. Corte. Se da a entender en el fallo que, como no se señala un apercibimiento para el evento que el denunciante no acompañe dentro del plazo fatal de cinco días los antecedentes fundantes:

No corresponde que la denuncia sea declarada inadmisible o se la desestime desde ya, menos que se la rechace una vez tramitado el juicio íntegramente. Para ello, habría sido necesario que el legislador lo hubiera señalado expresamente, v.gr., como lo hizo tratándose del artículo 54-1 de la Ley 19.968, en la medida que señala que si en el control de admisibilidad se advierte que la demanda no cumple los requisitos formales que establece el artículo 57, el tribunal debe ordenar que se subsanen sus defectos en el plazo que fije, bajo sanción de tenerla por no presentada.

y Leyes Complementarias, Tomo I, Santiago, Editorial Jurídica de Chile, 1996. La jurisprudencia referida, data del año 1964 .

4. Considérese en la línea penal insinuada, lo dispuesto por los artículos 223 número 1 del Código Penal 224 número 2, o el 225 número 1 y 2 del mismo Código. 
La remisión de la Corte a la regulación orgánica de los Tribunales de Familia, a fin de argüir en base a la inexistencia, teórica por lo demás, de un control de admisibilidad al modo de tales en sede laboral, es al menos, cuestionable. Si bien es efectiva la existencia de un apartado específico en la Ley 19.968, denominado «Admisibilidad y etapa de recepción» y que se conforma por dos artículos (54-1 y 54-2), ello no es capaz de sustentar, ante la inexistencia de uno similar o idéntico en materia procesal laboral en cualquiera de sus procedimientos, el que no sea posible declarar a la denuncia de vulneración de Derechos Fundamentales como inadmisible, desestimarla sin más, o rechazarla tramitado que sea el juicio al no acompañarse los antecedentes sustentantes a la misma, siguiendo la lógica de la Corte Suprema.

En rigor, desde la arista orgánica, la ausencia de un acápite en el que se regule de manera expresa y explícita que «uno o más jueces» del Tribunal Laboral, al modo de los Juzgados de Familia, realicen el control de admisibilidad de los variados requerimientos que se hagan', se entiende más como una decisión de técnica legislativa a la hora de agrupar las facultades de los jueces ante solicitudes con yerros, que ausencia de las mismas. O lo que sería peor, que en razón de adjudicar en tanto cuestión cierta que no existen tales facultades por no estar atribuidas a un juez en su normativa orgánica específica, deban asumirse los errores en el planteamiento de, v.gr. una denuncia de vulneración de derechos fundamentales e incluso sujetarse a lo señalado por el artículo 492 de Código del Trabajo.

En sede de Familia ya se anticipaba que se adoptó la decisión de regular en un apartado puntual, las facultades revisoras del juez en relación a la admisibilidad. Caben luego de efectuar tal análisis, dos posibilidades: ordenar se subsane la demanda en el plazo que el Tribunal fije si esta no cumple con los requisitos formales indicados en el artículo 57, bajo apercibimiento de tenerla por no presentada; o bien, rechazarla fundadamente de plano si apareciese que esta es manifiestamente improcedente, salvo si es que es la demanda contiene acciones de filiación y todas aquellas que digan relación con la constitución o modificación del estado civil de las personas, y las que tratan actos de violencia intrafamiliar.

¿Acaso el Tribunal del Trabajo carece de las facultades aludidas? La respuesta es negativa, puesto que las posee. Por ejemplo, si de la lectura de la demanda el Tribunal extrae que existen actuaciones administrativas y estas no son acompañadas a la demanda, el juez ordenará se presenten tales previo a proveer dentro del plazo de

5. Lo cual, en base a rigor textual contrastado con la realidad, es falaz, pues sabido y asumido es que no son directamente los jueces quienes realizan tal control, al existir funcionarios administrativos quienes lo efectúan en la Región Metropolitana, al menos. El juez o jueces, si bien suscriben la resolución que determina la admisibilidad de una demanda, por ejemplo, no son quienes directa y materialmente efectúan el análisis o control de admisibilidad, sin perjuicio que igualmente firman las resoluciones que la determinan. 
tres días bajo apercibimiento de tener por no presentada la demanda y archivar los antecedentes. Mismo apercibimiento se aplica si es que se demanda a una institución de previsión o seguridad social, y no se acompaña la resolución final de la entidad o de quién fiscalizó, según corresponda. Así mismo, no admitirá a tramitación la demanda si es que se desprendiera claramente la caducidad de la acción, declarándose de oficio aquello. Es decir, puede solicitar se subsane el error dentro de un término o bien, derechamente, no admitir a tramitación la demanda.

Las anteriores conclusiones, extraídas de la redacción expresa de los artículos 446 y 447 del Código del Trabajo, dan pie directo para que el juez establezca las consecuencias procesales indicadas. ¿Significará entonces, que no existe consecuencia alguna para el litigante temerario que hace caso omiso al término de cinco días del inciso segundo del artículo 490 del Código, y no acompaña antecedentes? Y ello, por el mero hecho que dicha norma u otra no señale apercibimiento específico en relación a la admisibilidad de esta denuncia, prácticamente en el mismo artículo, al modo del procedimiento de Familia. Una vez más, la respuesta a la cuestión formulada es negativa. El ya antes aludido artículo 491 del Código del Trabajo da cuenta de un control de admisibilidad de la denuncia, del que debieran decantar inexorablemente ante su no cumplimiento de los requisitos procesales, las opciones que el propio Código indica: subsanar incorporando los antecedentes probatorios dentro de cinco días, y ante la rebeldía tras vencerse dicho término fatal, que lisa y llanamente la denuncia no sea admitida a tramitación. Acto que no es sino, ya a riesgo de ser majadero, el resultado del cumplimiento estricto de las exigencias legales impuestas por el legislador a fin de evitar denuncias temerarias. Este último aspecto hace que sea posible concluir, que no se precisaría al amparo de la normativa y teoría transversal traída a colación, de un concreto llamamiento del legislador al juez laboral a tener por no admitidos a tramitación actos que no cumplan con los requisitos que la legislación le imponga a los legitimados.

\section{Al final del día, disquisiciones todas que no tienen que ver (únicamente) con la Tutela Efectiva de los Derechos Fundamentales del Trabajador}

Ya en la parte final del fallo (considerandos quinto al séptimo), la E. Corte inicia sus conclusiones desde la ya referida sinonimia que busca imprimirle a los conceptos de antecedentes y hechos, en el contexto del artículo 493 del Código, largamente atacada en este comentario. Empero, agrega a su batería conceptual la noción de «tutela judicial efectiva de los derechos de los trabajadores».

¿Acaso será ese el sentido de la «Tutela Judicial Efectiva de los derechos de los trabajadores»? ¿Una cuyo contenido básico e irreductible implica el acceso a los tribunales de justicia sin imponer trabas al ejercicio de las acciones conferidas por el legislador? ¿Trabas? ¿Obtener decisiones conformes a derecho, según el caso? ¿Y el 
Debido Proceso, cuando? ¿Son escindibles el Debido Proceso y la Tutela Judicial Efectiva? ¿Es que acaso el máximo Tribunal del país comprende como una posibilidad satisfactoria que los requisitos de admisibilidad son restricciones dables de eliminar cuando se trata de tutelar los derechos de la parte trabajadora y, con ello, obtener ésta expeditamente decisiones favorables? La respuesta a estos cuestionamientos, va dando cuenta de la forma en que la Corte Suprema estructura la forma en que los derechos en disputa han de ser interpretados.

Claramente debió existir, tanto en la especie como en el análisis de la situación en abstracto, la aplicación de un binomio que en el presente caso la lectura ofrecida por el máximo Tribunal olvidó. $\mathrm{O}$ al menos de la cual se desentendió: una en la que tanto el Debido Proceso como la Tutela Judicial Efectiva de los Derechos fuesen tenidas como garantías de las que gozan ambas partes, independientemente de cuál sea el proceso judicial en el que se batan. En palabras de Álvaro de Oliveira:

El derecho fundamental de acceso a la jurisdicción se traduce entonces en el poder de exigir del órgano judicial, en tiempo razonable, el desarrollo completo de sus actividades, tanto decisorias, con emisión de un pronunciamiento procesal o de mérito sobre el objeto de la pretensión procesal, como que pueda ser realizado efectivamente desde el punto de vista material. Todo eso debe conformarse al concepto de adecuación, con la proporcionalidad necesaria entre el derecho fundamental a un proceso justo y el derecho fundamental a una tutela jurisdiccional efectiva y adecuada (Álvaro de Oliveira, 2009: 192).

Aquello que el autor citado denomina bajo la noción de «adecuación», es el resultado de un maridaje que considera un equilibrio entre efectividad y seguridad en la operatividad del procedimiento, y al final del día, de los preceptos constitucionales en los que se inspiran. Uno en el que la búsqueda de la decisión ajustada a Derecho jamás podría tolerar que las formas sean plenamente apocadas por la naturaleza del procedimiento, en desmedro de la garantía del Debido Proceso y del Proceso Justo, visión más dinámica si se quiere, del Debido Proceso.

En semejante perspectiva, no se trata de un genérico derecho al proceso, asentado en derechos estáticos, sino que se intenta asegurar, a partir de los conceptos de ecuanimidad y de justicia, no sólo la suficiencia cuantitativa mínima de los «medios procesales», sino también un «resultado» cualitativamente diferenciado. De esa manera, a partir de las premisas anteriormente establecidas es posible extraer la consecuencia de que, en el cuadro de los derechos fundamentales constitucionales, el «derecho al proceso» no se caracteriza por un objeto únicamente formal o abstracto («proceso» tout court), sino que asume un contenido modal calificado («derecho al justo proceso»), que es exactamente la cara dinámica del «debido proceso legal» (Comoglio, 1999: 58). 
La indisociabilidad de los conceptos referidos -Debido Proceso y Tutela Judicial Efectiva- persigue evitar ejercicios procedimentales y hermenéuticos en el que su aplicación solo persiga ensalzar la efectividad de la institución en la que ingresan, haciendo que en su nombre puedan obviarse requisitos formales que contradictoriamente, puedan poner en jaque la propia efectividad del sistema ${ }^{6}$. La codificación de estas garantías en los cuerpos legales deviene en un asunto cuya componenda en el plano infraconstitucional, permite examinar cuan «adecuado» resulta ser un procedimiento en particular.

Tristemente, la visión que tiene la Corte Suprema es capaz de calificar como «trabas» los requisitos que el propio legislador ha establecido para la admisibilidad de la denuncia en materia de Tutela de Derechos Fundamentales en sede laboral. En virtud de tal lineamiento, alimentado sin duda por la línea argumentativa inconexa de la Tutela Judicial Efectiva con el Debido y Justo Proceso 7 , la Corte trae a colación una doctrina perteneciente a José Luis Ugarte referente al cómo debe entenderse al artículo 493 del Código del Trabajo. Expresa el máximo Tribunal, citando a Ugarte:

La regla del 493 C. Trab., no corresponde en sentido estricto a una regla de la etapa probatoria, sino a una regla de juicio, esto es, una regla que opera cuando el juez, al momento de dictar la sentencia, debe resolver quién debe soportar el costo del hecho que en el proceso no ha quedado plenamente acreditado, pero de cuya ocurrencia, por la presencia de indicios al respecto, se guarda razonable duda. En este caso, el hecho cuya razonable duda queda en el proceso -que no es sino el hecho de haber ocurrido la conducta lesiva de derechos fundamentales- afectará, a diferencia de la pauta distributiva normal de un proceso judicial, al demandado, quien sabe desde el inicio del proceso que en la acción de tutela existe, por expresa disposición legal, una distribución alterada de la carga material del costo probatorio (Ugarte, 2009: 220-222).

6. Interesante resultaría efectuar un estudio que arroje cuantas denuncias sin antecedentes fundantes de la vulneración de Derechos Fundamentales son declaradas admisible por los Tribunales del Trabajo, o que bien y con todo, a pesar de haber sido tramitadas, son rechazadas pues en ningún momento se acompañó al proceso prueba que acreditase la existencia de la afectación. Esta cuestión, lógicamente, incide en el funcionamiento de los Tribunales del Trabajo, al darle cabida a denuncias que no toleran un examen de admisibilidad siquiera liviano, incrementando la carga laboral de jueces y funcionarios. Hoy por hoy, en que resulta ser un hecho público y notorio el atochamiento crítico de los Tribunales del Trabajo en Santiago, resultaría particularmente interesante un estudio que establezca la incidencia de la admisibilidad de esta clase de denuncias en esta trama.

7. «El "proceso justo" lo es "justo" porque es garantía de la aplicación de las garantías procesales. Pero, ¡atención! nada más. No es "justo" porque en él se establezca la "verdad” (o sea, la manoseada "justicia” "mi justicia" o "tu justicia"). Como mucho, el "proceso justo" -que lo es "justo" por aplicar inexorablemente las garantías procesales-, lo que garantiza no es la "verdad" (o sea, la "justicia") sino el "convencimiento" de la parte respecto de que se ha desarrollado un "proceso justo"» (Lorca Navarrete, 2013: 14). 
$\mathrm{Al}$ alero de todo lo expuesto, la denominada «regla del 493 del Código del Trabajo» tiene una resonancia procesal y una incidencia que va más allá del momento de dictar sentencia, con precisión, de la determinación de quién debe tolerar que el hecho materia del proceso no haya quedado suficientemente bien acreditado. Esto, pues el núcleo de la norma se encuentra en los albores del proceso, en la interposición de la denuncia, inquiriendo que el denunciante dote de credibilidad básica a los dichos que conforman los hechos sustento de la denuncia para que esta sea declarada admisible por el Tribunal. Ergo, es la interposición de la denuncia y el examen de admisibilidad correlativo el primer momento en que la denuncia debe demostrar que es legítima la facilidad probatoria por la que deambulará el procedimiento, incidiendo por lo demás, en la dictación de la sentencia. En efecto,

Hay que destacar que no estamos en una situación pura y dura de inversión de la carga de la prueba, pues no basta con que el trabajador declare en su denuncia que se le vulneró un derecho fundamental para que, de esa manera, le corresponda íntegramente el peso de la prueba al demandado en orden a desvirtuar dicha aseveración. Ello no es así. Al trabajador se le exige una mínima carga de aportar antecedentes probatorios que sugieran que se ha producido la vulneración de sus derechos fundamentales. Introducidos esos antecedentes probatorios, ello no se traduce en que se deban dar por establecidos los hechos señalados por el actor, sino que hace operar una inversión de la carga de prueba en perjuicio del demandado, quien deberá probar que no realizó una conducta ilegítima que vulneró uno o algunos derechos fundamentales del actor (Bordalí, 2013: 238).

La lectura propuesta hace más dúctiles las formas del inciso $1^{\circ}$ del artículo 490 del Código del Trabajo, las que miradas desde la textualidad estricta, harían posible que el actor en estos procedimientos tenga que acompañar la totalidad de los documentos-antecedentes en los que su denuncia se sustente. Cuestión que se rechaza por no «adecuarse» a la naturaleza y al discurso propios y comprensibles de una acción que persigue tutelar las infracciones de un sujeto que se observa como el más fuerte en una relación interprivatos, y que ante una existencia acreditable de indicios por parte de la víctima mediante la incorporación de antecedentes a su denuncia, el ordenamiento jurídico esté presto a dar pronta respuesta. Se posibilita entonces la realización del derecho, de conformidad a parámetros adecuados de seguridad jurídica, mas, no de cualquier forma: «no se busca más el absoluto de la seguridad jurídica, sino la seguridad jurídica afectada de un coeficiente, de una garantía de realidad. En esa nueva perspectiva, la propia seguridad jurídica induce al cambio, al movimiento, visto que debe estar al servicio del objetivo mediato de permitir la efectividad del derecho fundamental» (Álvaro de Oliveira, 2009: 195). Por ello es que malamente puede entenderse como una «traba» al ejercicio de la Tutela Judicial Efectiva el que se le imponga al denunciante la obligación de acompañar a su denuncia 
antecedentes probatorios materiales que funden y doten de confiabilidad su batería fáctica, y que entonces, y solo entonces, pueda declarársele como admisible, y de ser así, nacería recién la obligación del denunciado de explicar los fundamentos de las medidas adoptadas y su proporcionalidad.

He ahí, en un esquema racional y adecuado, la complementariedad de los artículos 490 y 493 del Código del Trabajo. Una que comprende que malamente en un sistema respetuoso del Debido y Justo Proceso, las formas podrán estar por sobre dichas garantías procesales, imponiendo indicios por un mero relato, torciendo los pesos de la prueba sin mayor argumento que los quiebres dramáticos de una seguidilla de hechos sin sustento acompañado en el momento procesal puntual exigido por el legislador.

\section{Conclusiones}

- ¿Cómo comprende Chile operativamente la protección de los Derechos Fundamentales en sede laboral? La respuesta a dicha pregunta, más allá de las referencias positivas que se puedan realizar, debe necesariamente partir por la interpretación que de las mismas hacen los Tribunales Superiores de Justicia, especialmente de aquellas que le dan operatividad al procedimiento, $v . g r$. artículos 490 y 493 del Código del Trabajo.

- En este comentario se ha establecido lo erróneo que resulta sinonimizar «hechos de la denuncia-antecedentes fundantes», al abrirse el arco tutelar de los Juzgados Laborales sin mayores análisis de admisibilidad, incluso contra texto expreso. No se entiende, en fin, que lo que deben acompañarse son antecedentes probatorios que revistan de mínimos ribetes de credibilidad a una denuncia, que para bastarse a sí misma, no puede obedecer a una simple correlación de hechos.

- Una lectura armónica y coherente de la Excma. Corte, desde la gramática misma del texto legal, revela lo poco aconsejable que resulta interpretar las normas pertinentes conforme los criterios del DRAE. Se obvia en el examen de la Corte, el elemento lógico, básico para obtener un razonamiento acorde y sistemático con el resto de las instituciones que permean en la operatividad del procedimiento de vulneración de Derechos Fundamentales.

- Plazos fatales, apercibimientos y admisibilidades entran al mentado procedimiento. Ninguno, en verdad, es asumido derechamente en serio desde la perspectiva de su rol dentro de la tutela de estos derechos. Nada importa que el denunciante tenga cinco días para acompañar antecedentes, pues teniendo «hechos» (lo mínimo esperable y positivamente prescrito) la denuncia será 
admitida a tramitación. ¿Importa que el legislador establezca expresamente que los cinco días son fatales? Para nada, y ello en visión de la Corte no tendrá relevancia ni para admitir a tramitación la denuncia, ni para tramitarla, ni para desecharla ya en la etapa de adjudicación. Incluso, es posible configurar indicios sin antecedentes fundantes, y con ello forzar la suspensión de hechos al alero del artículo 492 del Código del Trabajo que, por qué, podrían solo estar en el papel de la denuncia.

- En nombre de la oficialidad es factible dar término a denuncias simplemente temerarias, pues como bien expresa el inciso primero del artículo 429 del Código del Trabajo, el juez deberá adoptar las medidas tendientes a evitar la «la prolongación indebida» del proceso. Empero, el continuar tramitando esta clase de procedimientos, viciados al carecer la denuncia de todos sus requisitos, hace que el juez culmine subsanando las deficiencias técnicas del único legitimado activo en el procedimiento en comento, mutando en su rol de adjudicador al de parte. ¿Por qué no encauzar la admisibilidad ordenando de oficio, a título de medida prejudicial, la declaración de testigos, o la exhibición de documentos, a fin de cimentar los aludidos «antecedentes fundantes» y en caso favorable al amparo del resultado de estas gestiones, recién dar curso a estas denuncias?

- La E. Corte Suprema pretende argüir su posición en la materialización de la Tutela Judicial Efectiva de los Derechos Fundamentales de los trabajadores. Se tuvo oportunidad de señalar el insuficiente contenido de dicha institución en un marco en donde lo mínimo que uno pudiera esperar del máximo Tribunal del país, es el respeto a derechos tales como el del Debido Proceso y el Justo Proceso. Tal arista es obviada en el análisis de la Corte, descartando por lo mismo, el contenido doctrinal de estas garantías. Se introduce la noción de «adecuación», en un escenario en el que se procura garantizar la aplicación de las garantías procesales para todas las partes intervinientes, sin obviar que la efectividad del procedimiento debe admitir licencias interpretativas que hagan más laxo el contenido normativo que regular la tutela de esta clase de derechos. Con todo, jamás las formas podrán superar la tutela por la vigencia de todos los Derechos Fundamentales.

- El mensaje que permea para la ciudadanía, es que es posible introducir al tráfico jurídico una denuncia basada meramente en hechos. Desde la perspectiva de la utilidad, evidente es que el mayor beneficiado con esto es el denunciante, para quién bastará un buen relato (y con ello dar por entendido que acompañó antecedentes suficientes) para hacer operar la facilidad probatoria propia del procedimiento de Tutela del Código del Trabajo, y forzar el nacimiento de in- 
dicios suficientes. Ahora bien, desde la arista del Estado de Derecho, concepto abstracto en su extensión pero recurrente en denuncias de Tutela de Derechos Fundamentales en las que se perseguiría su teórico restablecimiento mediante la condena del juez de grado, tenemos que es la propia Corte Suprema la que culmina amparando formas antijurídicas que terminan contrariando otras garantías constitucionales que terminan en último plano. Garantías que no son sino las reglas del juego para todos ante un poder que tiene por base en la imparcialidad, y la legalidad el sustrato último de su legitimidad. Así, si a quien recurro para procurar se aplique el Derecho falla contra él, legitimo es preguntarse, al fin, ¿quién vigilará al vigilante?

\section{Referencias}

Álvaro de Oliveira, Carlos Alberto (2009). «El derecho a la tutela jurisdiccional efectiva desde la perspectiva de los derechos fundamentales». Revista de Derecho (Valdivia), 22 (1): 185-201.

Andreucci Aguilera, Rodrigo (2008). «Los conceptos de la Corte Suprema sobre interpretación de la ley a través de sus sentencias». En Nomos (Universidad Viña del Mar), 1.

Bordalí Salamanca, Andrés (2013). «La igualdad de las partes en los procesos judiciales chilenos». En Fernando Muñoz León (ed.). Igualdad, inclusión y derecho. Lo político, lo social y lo jurídico en clave igualitaria. Santiago: Lom Ediciones.

Claro Solar, Luis (1992). Explicaciones de Derecho Civil Chileno y Comparado. Bogotá: Editorial Jurídica de Chile.

Comoglio, Luigi Paolo (1999). Lezione Sul Processo Civile (en colaboración con Corrado Ferri y Michele Taruffo). Bologna: Ed. Il Mulino.

Cordero Quinzacara, Eduardo (2006). «La dogmática constitucional de la propiedad en el derecho chileno». En Revista de Derecho, 19 (1): 125-148.

Díaz García, Iván (2015). «Objetivo del recurso de unificación de jurisprudencia laboral». Revista Ius et Praxis, 21 (1): 423-448.

Ducci Claro, Carlos (2005). Derecho Civil. Parte General. Santiago: Jurídica.

Lorca Navarrete, Antonio María (2013). «El denominado "Proceso Justo"». En Revista de Derecho Ius et Ratio, 1 (1).

Palavecino Cáceres, Claudio (2014). «El procedimiento de tutela de derechos fundamentales del trabajador en Chile». Revista Chilena de Derecho del Trabajo y de la Seguridad Social, 5 (9): 33-45.

Ugarte Cataldo, José Luis (2009). «Tutela laboral de derechos fundamentales y carga de la prueba». Revista de Derecho (Pontificia Universidad Católica de Valparaíso), 33: 215-228. 
WALter DÍAz, Rodolfo y Gabriela Lanata Fuenzalida (2007). Régimen legal del nuevo proceso laboral chileno. Santiago: Editorial LexisNexis.

\section{Sobre el autor}

Sebastián Pizarro Contreras es abogado de la Universidad Viña del Mar, Diplomado en Derecho Laboral de la Empresa de la Universidad de Los Andes, candidato a Magister en Derecho del Trabajo y de la Seguridad Social de la Universidad de Chile, y estudiante del Doctorado en Derecho de la Universidad de Chile. 